NBER WORKING PAPER SERIES

\title{
THE REALLOCATION OF COMPENSATION IN RESPONSE TO HEALTH INSURANCE PREMIUM INCREASES
}

\author{
Dana P. Goldman \\ Neeraj Sood \\ Arleen A. Leibowitz \\ Working Paper 9540 \\ http://www.nber.org/papers/w9540
}

NATIONAL BUREAU OF ECONOMIC RESEARCH

1050 Massachusetts Avenue

Cambridge, MA 02138

March 2003

The views expressed herein are those of the authors and not necessarily those of the National Bureau of Economic Research.

(C2003 by Dana P. Goldman, Neeraj Sood, and Arleen A. Leibowitz. All rights reserved. Short sections of text not to exceed two paragraphs, may be quoted without explicit permission provided that full credit including Cnotice, is given to the source. 
The Reallocation of Compensation in Response to Health Insurance Premium Increases Dana P. Goldman, Neeraj Sood, and Arleen A. Leibowitz NBER Working Paper No. 9540

March 2003

JEL No. I2

\section{$\underline{\text { ABSTRACT }}$}

This paper examines how compensation packages change when health insurance premiums rise. We use data on employee choices within a single large firm with a flexible benefits plan; an increasingly common arrangement among medium and large firms. In these companies, employees explicitly choose how to allocate compensation between cash and various benefits such as retirement, medical insurance, life insurance, and dental benefits. We find that a $\$ 1$ increase in the price of health insurance leads to 52-cent increase in expenditures on health insurance. Approximately $2 / 3$ of this increase is financed through reduced wages and $1 / 3$ through other benefits.

\section{Dana P. Goldman \\ RAND Graduate School \\ 1700 Main Street}

P.O. Box 2138

Santa Monica, CA 90407-2138

and NBER

dgoldman@rand.org

Arleen A. Leibowitz

Department of Policy Studies

UCLA

6345 Public Policy Building

Box 951656

Los Angeles, CA 90095-1656

arleen@ucla.edu
Neeraj Sood

RAND Graduate School

1700 Main Street

P.O. 2138

Santa Monica, CA 90407-2138

sood@rand.org 


\section{INTRODUCTION}

Many companies have redesigned their benefits plans to require employees to pay the full marginal cost (pre-tax) of more expensive plans. Such 'fixed subsidy' schemes have been discussed for over two decades (Enthoven, 1978), but have gotten more attention recently as health insurance premiums escalate. These schemes are more efficient if workers have different tastes for health insurance (Levy, 1997), and research has shown that employee insurance choices are quite responsive to these arrangements (Buchmueller and Feldstein, 1996; Cutler and Reber, 1998).

What is less clear is how the total compensation package - e.g. retirement benefitschanges when health insurance premiums rise. If the price elasticity of demand for health insurance is less than one - and the evidence suggests it is - then workers will increase expenditures on health insurance as their share of premiums rise. But if labor supply and demand remains fixed, then total compensation should not change, just its composition into health insurance, wages, and other benefits (Smith and Ehrenberg, 1983; Summers, 1989). This is easiest to see in cafeteria-style plans, where employers make a defined contribution to all employer-related benefits, and higher health insurance premiums must induce changes in composition of total compensation-either in lower after-tax wages or in decreased contributions to other benefits.

This paper examines how workers change their compensation package in response to changing health insurance premiums. To the extent that workers do not completely substitute away from rising premiums, we are particularly interested in whether employees finance health insurance by reducing current income (essentially wages) or other benefits (life insurance, disability insurance, and other benefits).

We know of no other work in this area, although there is a substantial literature on the tradeoff between wages and fringe benefits. Much of this work tries to estimate the substitution between benefits and wages using data aggregated at the firm or industry level (Woodbury, 
1983). These estimates are somewhat limited because the fringes are often allocated as part of a collective bargaining agreement or a less explicit process based on worker preferences that calls into question the underlying assumptions of flexible wages and costless mobility (Freeman, 1981; Goldstein and Pauly, 1976). Others have tried to estimate the relationship with employeelevel data from multiple firms. The implausible result that wages and benefits do not tradeoffholding productivity fixed — are best explained as bias due to unobserved heterogeneity (Smith \& Ehrenberg, 1983).

We try to avoid these problems by focusing on employee choices within a single large firm with a flexible benefits plan. Under such an arrangement, employees explicitly choose how to allocate compensation between cash and various benefits, such as retirement, medical insurance, life insurance, and dental benefits. Such plans cover $52 \%$ of workers in medium and large firms, and the proportion is growing, so they are interesting to study in their own right (BLS, 1999). The effect of health insurance premiums on compensation is identified by the substantial variation in premiums across years.

The results suggest that about two-thirds of the premium increase is financed out of cash wages and the remaining one-thirds is financed by a reduction in benefits. However, these findings come from only a single firm — and hence limit our ability to draw inferences to the general population - but they do suggest that the relationship between health insurance benefits, and wages warrants further investigation.

\section{DATA}

The original data set consists of three years (1989-1991) of earnings and benefit information for employees under age 65 at a single U.S. company. ${ }^{1}$ While these data are 10 years old, this period is relevant to the current debate about health care costs because health insurance premiums are rising rapidly today, as they were in the late 1980's and early 1990's. It

${ }^{1}$ These data were obtained from a benefits consulting firm. The terms of the data release precluded us from providing detail about the company, including its industry. 
also is comparable to periods studied in other research looking at health plan switching that found large elasticities. Furthermore, there is little reason to expect that human behavior with regard to insurance choice has changed much over the last decade. Our study focuses on a sample of single employees who signed up for a health insurance plan ${ }^{2}$. Families are excluded because we have no information on the health insurance opportunity sets of spouses, and how those might change over time. These employees are geographically dispersed across 47 states. The data also include a limited set of demographic controls such as age and sex. Since we analyze changes in employees' expenditures relative to the previous years, we restrict our attention to employees with atleast two years of data - resulting in an analysis sample of 7,896 employee-year observations.

Table 1 presents descriptive statistics for the sample. Total compensation averaged $\$ 27,412$. Approximately $2.3 \%$ of compensation $(\$ 622)$ went towards the purchase of health insurance, $1.1 \%$ (\$286) went towards purchase of other benefits within the cafeteria plan and the remaining compensation was taken as wages. Benefits appear low as a fraction of total compensation because our benefits and compensation measures do not include legally mandated benefits such as Social Security and workers' compensation, nor do they include the employer contributions towards health insurance and retirement.

\section{[INSERT TABLE 1 HERE]}

Employees in this firm were given a menu of benefit options. To finance these benefits each employee was also given a completely fungible credit allocation that depends on salary and job tenure. However, the credit allocation does not determine expenses on benefits as employees can make additional pre-tax deductions from their salaries or wages to finance benefits. In addition, employees can also choose to cash -out most of their credit allocation.

\section{[INSERT TABLE 2 HERE]}

2 We excluded a small number of single employees (222) who did enroll in the employers health plan despite a free catastrophic health plan option. Clearly these employees had other outside insurance options . 
Table 2 shows the mean, standard deviation and probability of contributing, for each benefit component of total compensation in 1990. Employees spend their total compensation on wages, health insurance, dental insurance, life insurance, disability insurance, health care savings account, ${ }^{3}$ retirement plan, accident insurance, survivor insurance, and life insurance to cover dependents. Some of these components are rarely used, and the contributions are small. Rather than estimate models for all of them, we aggregate these into three broad categories - wage, health insurance and other benefits. Although the benefits in the "other benefits" category are diverse they are conceptually related in that most of them are insurance products that involve forgoing current consumption (in terms of premiums) for future and uncertain payouts.

Table 3 shows the enrollment in each year for the different health insurance plans offered by the firm. The company offers two types of health insurance plans: fee-for-service (FFS) plans and HMOs. Table 3 shows that within the FFS class, there are three types of plans: a catastrophic plan with a deductible of 5\% of salary, a low option plan with deductibles of $\$ 300$ for individuals, and a high option with deductibles of $\$ 150$. The other plans consist of 43 HMOs nationwide, with each employee's available options depending on state of residence and year.

\section{[INSERT TABLE 3 HERE]}

As with most employers, this company contributes towards the purchase of these plans. Unlike many employers, however, the amount does not vary by plan choice, but depends only on the number of beneficiaries. By not contributing more generously to more expensive plans, the employer makes employees face the full marginal cost of more generous coverage (on a pre-tax basis). The employer's 'fixed subsidy' is equal to the premium for the catastrophic plan.

\section{[INSERT TABLE 4 HERE]}

Table 4 shows the variation in the copremiums - the amount of total premium paid by the employee - across plans. HMO copremiums rose faster in absolute and percentage terms from

\footnotetext{
3 An employee can deposit funds free of income taxes in a health care savings account to
} reimburse qualifying health care expenses. Any unused funds left in the account at the end of the year are forfeited. 
1989 to 1990 . From 1990 to 1991, the premiums in the low-deductible FFS plan rose faster than the HMO premiums, but the HMO premiums still increased substantially. The drop in enrollment in both types of plans (shown in Table 3) during that period may reflect these premium increases. Table 4 also shows that HMO premiums vary considerably over this period, sometimes falling as much as $26 \%$ or increasing by $34 \%$ year-to-year. We exploit this considerable variation to identify our models. 


\section{METHODS}

We model how the allocation of total compensation varies with an increase in costs of health insurance for employees. That is, we want to know the responsiveness of each component of total compensation (wages, health insurance expenditures, other benefits) to changes in health insurance prices for employees. The key challenge is to measure changes in the price of health insurance for employees.

Ideally, a measure of increase in the price of health insurance would show the difference in the costs of obtaining a reference level of utility due to a new vector of health insurance copremiums. However, the problem with constructing this "true price index" is that utility is not measurable. To circumvent this problem alternative estimates of price changes calculate the difference in costs of obtaining a fixed basket of goods at a new vector of prices. Two wellknown indices are the Laspeyres price index that measures the difference in costs of purchasing the base year basket of goods and the Paasche price index that measures the difference in costs of purchasing the current year basket of goods. Although these fixed weight indices are easy to calculate they induce some bias in the measurement of cost changes. Most importantly, these indices ignore the possibility of substitution among goods due to changes in relative prices. For example, employees might switch to cheaper health plans in response to changes in the relative price of health plans (This is true in our data as shown in Tables 3 and 4). Thus using base year enrollment in different health plans as weights for the price index will overstate the true increase in the cost of health insurance. Fisher (1922) proposed an index that is the geometric mean of the Laspeyres and Paasche price index. The Fisher price index has much lower substitution bias and other desirable properties compared to other fixed weight price indices (Diewert, 1976). In particular it closely approximates the true cost index if preferences are homothetic. Due to its desirable properties most statistical agencies around the world including the Bureau of Economic Analysis at the US Commerce Department have started using the Fisher index to measure 
changes in prices and quantities (Boskin et al., 1998). We also use the Fisher price index to measure changes in prices.

Since HMO plan options and copremiums vary with the state we create separate indices for each state in our data. If the vector $P_{s, t}=\left(P_{1, s, t}, P_{2, s, t}, . ., P_{j, s, t}, . ., P_{J, s, t}\right)$ represent the insurance copremiums for each of the $J$ health plans offered in each state $s$ in year $t$ and the vector $Q_{s, t}=\left(Q_{1, s, t}, Q_{2, s, t}, . ., Q_{j, s, t}, . ., Q_{J, s, t}\right)$ represents the percentage of employees enrolled in each of the $J$ health plans in state $s$ in year $t$, then the Fisher index for state $s$ in year $t$ is defined as ${ }^{4}$ :

$$
\text { Fisher }_{s, t}=\sqrt{\left(\frac{P_{s, t} \cdot Q_{s, 89}}{P_{s, 89} \cdot Q_{s, 89}}\right)\left(\frac{P_{s, t} \cdot Q_{s, 91}}{P_{s, 89} \cdot Q_{s, 91}}\right)}
$$

Finally we create a price of insurance variable for each state $s$ in year $t\left(\right.$ price $\left._{s, t}\right)$ by multiplying the Fisher index for each state-year with the average copremiums in that state in 1989. This essentially rescales the unit-less Fisher index to 1989 copremium dollars in each state and thus makes our regressions results easy to interpret.

$$
\text { Price }_{s, t}=\text { Fisher }_{s, t} *\left(P_{s, 89} \cdot Q_{s, 89}\right)
$$

We estimate separate employee fixed-effects models for each component of total compensation. Essentially, an employee fixed-effects model controls for employee-specific time invariant unobservables (such as preferences for insurance) and primarily uses variation in employee choices and prices overtime to identify parameter estimates. Models that ignore these fixed effects will produce biased estimates if the employee-specific unobservables are correlated with our explanatory variables. If $i$ and $t$ subscript the employee and year then our empirical model can be summarized by the following equations:

$$
\begin{aligned}
& \text { Wage }_{i, t}=\alpha_{i}^{\text {wage }}+\delta^{\text {wage } \text { Price }_{i, t}+\beta^{\text {wage }} X_{i, t}+\varepsilon_{i, t}^{\text {wage }}} \\
& \text { Benefit }_{i, t}=\alpha_{i}^{\text {benefit }}+\delta^{\text {benefit }} \text { Price }_{i, t}+\beta^{\text {benefit }} X_{i, t}+\varepsilon_{i, t}^{\text {benefit }} \\
& \text { Health Insurance }_{i, t}=\alpha_{i}^{\text {health }}+\delta^{\text {health }^{\text {Price }}}{ }_{i, t}+\beta^{\text {health }} X_{i, t}+\varepsilon_{i, t}^{\text {health }} \\
& \text { Total Compensation }_{i, t}=\text { Wage }_{i, t}+\text { Benefit }_{i, t}+\text { Health Insurance }_{i, t} \forall i, t
\end{aligned}
$$


Where, $\alpha^{k}$ represents the employee fixed effects for benefit $k, \delta^{k}$ measures the increase in expenditures on wage or benefit $k$ due to a one dollar increase in the price of health insurance, and similarly the vector $\beta^{k}$ measures the changes in benefit $k$ due to changes in other covariates $X$ in our model. Equations (6) is an accounting identity and states that expenditures on wages, health insurance and other benefits add up to the total compensation of the employee. Equation (6) along with the three behavioral equation (3), (4) and (5) also implies that $\sum_{k} \delta^{k}=0$. That is, given that total compensation is fixed, any change in health insurance expenditures due to rising health insurance prices must be financed entirely by changes in benefits or wages.

To better illustrate our results we also compute the expenditure elasticity of each benefit category $k$ with respect to the health insurance price at the mean benefit allocations in 1989 .

$$
\text { (7) } \quad \xi^{k}=\frac{\delta^{k} * \bar{P}_{89}}{\bar{E}_{89}^{k}}
$$

Where, $\xi^{k}$ measures the percentage change in expenditures on benefit $k$ due to a one percent change in the price of health insurance, $\delta^{k}$ is the parameter estimate from equations (3) to (5), $\bar{P}_{89}$ is the mean health insurance price in 1989 and $\bar{E}_{89}^{k}$ is the mean expenditure on benefit $k$ in 1989.

\section{RESULTS}

The parameter estimates from models (3) to (5) are presented in the Table 5. The results show that a $\$ 1$ increase in the price of health insurance leads to a 52 cents increase in health insurance expenditures. This 52 cent increase in health insurance expenditures is financed by a 37 cents reduction in take home wages and a 15 cents reduction in other benefits. Thus approximately $70 \%$ of the increase in health insurance expenditures due increase in prices is financed by wage reductions. Put in elasticity terms, each $100 \%$ increase in the price of health insurance leads to a $50 \%$ increase in health insurance expenditures, a $1 \%$ decrease in take home wages, and a $28 \%$ decrease in other benefits. 


\section{DISCUSSION}

Our results suggest that employees facing an increase in the price of health insurance respond by lowering their level of insurance coverage. However, employees do not completely substitute away from health insurance, in fact increases in prices lead to increases in health insurance expenditures. These results accord well with the previous literature, which also found that the price elasticity of demand for health insurance was less than 1 (Buchmueller and Feldstein, 1996; Cutler and Reber, 1998).

Increases in expenditures on health insurance are accommodated by reducing both the take-home income and other benefits such as life insurance, disability insurance, dental insurance and retirement benefits. Thus, our results suggest that rising health insurance prices not only reduce resources for current consumption but also lower insurance purchases against a variety of risks. If health insurance prices continue to rise and individuals continue to reduce their purchase of health insurance and other insurance products that might leave them vulnerable to health, mortality, disability and other significant risks in the long run.

Our results also show that when employees are given the choice of absorbing premium increases through salary reductions or limiting expenditures on health and other benefits, they primarily choose to reduce take-home pay. This choice might reflect the advantage to employees of retaining non-taxed compensation in the form of benefits, and instead reducing taxable income. This suggests, that employers who trade off wage increases for increases in health insurance premiums are reallocating compensation in a way that workers have shown they prefer when they are provided options within flexible spending plans. 


\section{REFERENCES}

Boskin, M. J., Dulberger, E. R., Gordon, R. J., Griliches, Z., Jorgenson, D. W. (1998). Consumer Prices, the Consumer Price Index, and the Cost of Living. Journal of Economic Perspectives, 12(1): 3-26.

Buchmueller, T. C., Feldstein, P. J. (1996). Consumer's Sensitivity to Health Plan Premiums: Evidence from a Natural Experiment in California. Health Affairs, 15(1):143-151.

Bureau of Labor Statistics (1999). Employee Benefits in Medium and Large Private Establishments. News Release, January 7, 1999.

Cutler, D. M., Reber, S. J. (1998). Paying for Health Insurance: The Trade-off Between Competition and Adverse Selection. Quarterly Journal of Economics, 113(2):433-66.

Diewert, E. W. (1976). Exact and Superlative Index Numbers. Journal of Econometrics, May (4): $115-45$.

Enthoven A. C. (1978). Consumer-Choice Health plan (second of two parts). A national-healthinsurance proposal based on regulated competition in the private sector. $N$ Engl J Med (298):709-720.

Fisher, I. (1922). The Making of Index Numbers. Boston: Houghton Miffin.

Freeman, R. B. (1981). The Effect of Unionism on Fringe Benefits. Indust Labor Relat Rev, 34(4):489-509. 
Goldstein, G. S., Pauly, M. V. (1976). Group Health Insurance as a Local Public Good, in Rosset, R. R., editor. The Role of Health Insurance in the Health Services Sector. New York, NY: National Bureau of Economic Research, 73-110.

Levy, H. (1997). Who Pays for Health Insurance? Employee Contributions to Health Insurance Premiums. Princeton, NJ: Princeton University Working Paper.

Smith, R. S., Ehrenberg, R. G. (1983). Estimating Wage-Fringe Trade-Offs: Some Data Problems. In: Triplett, J. E., editor. The Measurement of Labor Cost. NBER Studies in Income and Wealth, Vol. 48. Chicago, IL: University of Chicago Press, 347-369.

Summers, L. H. (1989). Some Simple Economics of Madated Benefits. American Economic Review, 79(2):177.

Woodbury, S. A. (1983). Substitution Between Wage and Nonwage Benefits. American Economic Review, 73:166-182. 
Table 1. Descriptive Statistics

$$
(\mathrm{N}=7,896 \text { employee-years })
$$

\begin{tabular}{|c|c|c|c|c|}
\hline Variable & Mean & Std. Dev. & Minimum & Maximum \\
\hline Age & 35.1 & 10.8 & 18 & 64 \\
\hline Tenure (years) & 6.1 & 6.5 & 0 & 44 \\
\hline Female & 0.70 & 0.45 & 0 & 1 \\
\hline Health Insurance Benefit ${ }^{\mathrm{a}}$ & $\$ 622.7$ & $\$ 235.9$ & 0 & $\$ 1,428$ \\
\hline Other Fringe Benefits ${ }^{\mathrm{a}}$ & $\$ 285.8$ & $\$ 279.8$ & 0 & $\$ 5,335$ \\
\hline Net Wages $^{\mathrm{a}}$ & $\$ 26,503.5$ & $\$ 11,581.9$ & $\$ 6,593$ & $\$ 109,303$ \\
\hline Total Compensation ${ }^{\mathrm{a}, \mathrm{b}}$ & $\$ 27,412.0$ & $\$ 11,732.6$ & $\$ 7,277$ & $\$ 110,994$ \\
\hline
\end{tabular}

Notes

${ }^{\mathrm{a}}$ All amounts are in 1989 constant dollars.

${ }^{\mathrm{b}}$ Total compensation includes wages, health insurance and other benefits. 
Table 2. Employee Expenditures on Benefits in 1990

$$
(\mathrm{N}=2,934)
$$

\begin{tabular}{lccc}
\hline Benefit & & & \% Making \\
Category & Mean & Std Dev & Contribution \\
\hline Components of Total Compensation & 633 & 221 & 100 \\
Health Insurance & 289 & 267 & 94 \\
\hline Other Benefits & 38 & 116 & 34 \\
$\quad$ Life Insurance & 70 & 66 & 72 \\
$\quad$ Long-Term Disability & 13 & 21 & 50 \\
Accident Insurance & 1 & 1 & 1 \\
Dependent Life Insurance & 0 & 0 & 0 \\
Survivor Insurance & 11 & 58 & 6 \\
$\quad$ Retirement & 33 & 165 & 76 \\
Health Care Expense Acct & 123 & 71 & 100 \\
Dental Insurance & 26,289 & 11,451 & \\
\hline Wages & & & \\
\hline
\end{tabular}

Notes

All amounts are in 1989 constant dollars.

Total compensation includes wages, health insurance and other benefits. 
Table 3. Employee Insurance Choices, 1989 to 1991

\begin{tabular}{lcccc}
\hline \multirow{2}{*}{$\begin{array}{l}\text { Plan Type } \\
\text { FFS }\end{array}$} & Deductible & $\mathbf{1 9 8 9}$ & $\mathbf{1 9 9 0}$ & $\mathbf{1 9 9 1}$ \\
\cline { 3 - 5 } & & & & \\
Catastrophic & $5 \%$ of salary & 6.1 & 8.8 & 15.0 \\
High Deductible & $\$ 300$ & 8.5 & 10.0 & 13.6 \\
Low Deductible & $\$ 150$ & 42.6 & 39.3 & 34.0 \\
HMO* & & 42.8 & 41.9 & 37.4 \\
\hline & & & & \\
\hline
\end{tabular}

Notes

* There are 43 different HMOs offered-we do not break out enrollment by each plan as we do for FFS. 
Table 4. Variation in Employee Copremiums

\begin{tabular}{|c|c|c|c|c|}
\hline Type of Plan ${ }^{a}$ & $\begin{array}{l}\text { Number } \\
\text { of Plans }\end{array}$ & Co-Premium, $1989^{b, c}$ & $\begin{array}{l}\text { Co-Premium, } 1990^{\mathrm{b}, \mathrm{c}} \\
(\% \text { Increase } 89-90)\end{array}$ & $\begin{array}{l}\text { Co-Premium, } 1991^{\mathrm{b}, \mathrm{c}} \\
\text { (\% Increase 90-91) }\end{array}$ \\
\hline FFS $/ 5 \%$ of Salary & 1 & 0 & 0 & 0 \\
\hline $\mathrm{FFS} / \$ 300$ & 1 & $\$ 490$ & $\begin{array}{c}\$ 521 \\
(6.33 \%)\end{array}$ & $\begin{array}{c}\$ 525 \\
(0.77 \%)\end{array}$ \\
\hline $\mathrm{FFS} / \$ 150$ & 1 & $\$ 630$ & $\begin{array}{c}\$ 705 \\
(11.91 \%)\end{array}$ & $\begin{array}{c}\$ 812 \\
(15.17 \%)\end{array}$ \\
\hline HMO & 43 & $\$ 661$ & $\begin{array}{c}\$ 750 \\
(13.46 \%)\end{array}$ & $\begin{array}{c}\$ 825 \\
(10.00 \%)\end{array}$ \\
\hline $\begin{array}{l}\text { HMO Premium } \\
\text { Range }\end{array}$ & & $\$ 489$ to $\$ 946$ & $\begin{array}{l}\$ 455 \text { to } \$ 1,110 \\
(-26 \% \text { to } 34 \%)\end{array}$ & $\begin{array}{l}\$ 549 \text { to } \$ 1,428 \\
(-6 \% \text { to } 29 \%)\end{array}$ \\
\hline
\end{tabular}

Notes

${ }^{\mathrm{a}}$ The last row in this column shows the range of copremium and percent increase from previous years for the HMO plans.

${ }^{\mathrm{b}}$ The HMO copremium for each employee-year observation is calculated as the average copremium for enrolling in an HMO in that year for the employees state of residence. The HMO copremium reported is average copremium across all employees.

${ }^{\mathrm{c}}$ All copremiums are in 1989 constant dollars 
Table 5. Employee Fixed-Effect Model of Increase in Health Insurance Price on Allocation of Total Compensation

\begin{tabular}{|c|c|c|c|c|c|c|}
\hline \multirow[b]{2}{*}{ Variable } & \multicolumn{3}{|c|}{ Wages } & \multicolumn{3}{|c|}{ Other Benefits } \\
\hline & Coefficient & Std Error & $t$-statistic & Coefficient & Std Error & t-statistic \\
\hline Price & -0.3658 & 0.1205 & -3.04 & -0.1513 & 0.0815 & -1.86 \\
\hline Age & -16.9709 & 30.2048 & -0.56 & 108.8262 & 20.4346 & 5.33 \\
\hline Age Square & 0.0568 & 0.1602 & 0.36 & -0.9466 & 0.1084 & -8.73 \\
\hline Tenure & 49.0654 & 26.2687 & 1.84 & -64.4919 & 18.0625 & -3.57 \\
\hline Total Compensation & 0.9870 & 0.0023 & 413.22 & 0.0074 & 0.0016 & 4.61 \\
\hline Intercept & -97.6600 & 797.7172 & -0.12 & $-1,963.9660$ & 539.6825 & -3.64 \\
\hline \multicolumn{7}{|c|}{ Health Insurance Expenditures } \\
\hline Variable & Coefficient & Std Error & $t$-statistic & & & \\
\hline Price & 0.5171 & 0.0827 & 6.25 & & & \\
\hline Age & -91.8554 & 20.7380 & -4.43 & & & \\
\hline Age Square & 0.8897 & 0.1100 & 8.09 & & & \\
\hline Tenure & 15.4264 & 18.3307 & 0.84 & & & \\
\hline Total Compensation & 0.0055 & 0.0016 & 3.36 & & & \\
\hline Intercept & 2061.6290 & 547.6962 & 3.76 & & & \\
\hline \multicolumn{7}{|c|}{ Expenditure Elasticity } \\
\hline & Coefficient & Std Error & t-statistic & & & \\
\hline Wages & -0.0083 & 0.0027 & -3.04 & & & \\
\hline Other Benefits & -0.2870 & 0.1543 & -1.86 & & & \\
\hline Health Insurance & 0.5136 & 0.0821 & 6.25 & & & \\
\hline
\end{tabular}

